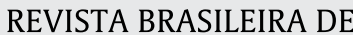

\section{A new species of the Gnamptogenys Mordax subgroup (Hymenoptera: Formicidae), with an Identification key to the species within the subgroup}

\author{
Frederico S. R. Marcineiro ${ }^{1}$ (1), John Lattke $^{1}$ \\ Universidade Federal do Paraná, Centro Politécnico, Departamento de Zoologia, Setor de Ciência Biológicas, Laboratório de \\ Biosistemática de Formigas, Curitiba, PR, Brasil
}

\section{A R T I C L E I N F O}

\section{Article history}

Received 25 October 2019

Accepted 06 April 2020

Available online 01 June 2020

Associate Editor: Jeffrey Sosa-Calvo

\section{Keywords}

Ants

Atlantic Forest

Morphology

Taxonomy

\begin{abstract}
A B S T R A C T
We describe, Gnamptogenys rugimala n. sp, a very distinct new species of the ectatommine genus Gnamptogenys, from specimens collected in forests of southeastern Brazil. We provide some data about G. rugimala n. sp occurrence and ecology as well as a species identification key for the mordax subgroup.
\end{abstract}

\section{Introduction}

The ectatommine ant genus Gnamptogenys Roger, 1863 has a distribution ranging from the Neotropics to the southern Nearctic and from Indomalaysia to Australia. They are usually found in the leaf litter of tropical and subtropical forests, commonly nesting in subterranean chambers or in rotten logs. In his revision of the New World Gnamptogenys, Lattke (1995) proposed six groups and eleven subgroups. One of these groups is the mordax group, which is divided into four subgroups. The mordax subgroup, which is currently represented by five species, is defined by the following suite of characters: subfalcate mandibles with a smooth and shining dorsal surface; a concave anterior clypeal margin with rounded lamellar sides; a well-impressed metanotal groove; a slightly pedunculate petiolar node; and a subpetiolar process that projects anterad (Lattke, 1995).

The species G. boliviensis Lattke, 1995; G. continua (Mayr, 1887); G. interrupta (Mayr, 1887); G. mordax (Smith, 1858) and G. stellae Lattke, 1995 considered collectively range from Veracruz (central
Mexico) to southeastern Brazil (Guénard et al., 2017). Longino (1998) found consistent morphological differences within species determined as $G$. mordax and $G$. interrupta, a situation that suggests the presence of cryptic species within each nominal species. Little is known of their natural history except for their preference for nesting and foraging in the leaf litter and decomposing wood on the ground (Lattke, 1990). Midden contents from a few nests of $G$. mordax and $G$. interrupta in Venezuela suggest at least some preference for preying upon beetles (Lattke, 1990).

During the routine curation of Gnamptogenys samples in the Museu de Zoologia da Universidade de São Paulo (MZSP) we found two conspecific specimens from two different localities in southeast Brazil belonging to the mordax species subgroup with a unique combination of character states not seen in any other of the known species. We describe this new species (Fig 1) and present an identification key to species of this subgroup.

\footnotetext{
* Corresponding author.

E-mail: frederico.marcineiro@gmail.com (F.S.R. Marcineiro).
} 


\section{Material and methods}

Morphological terms used follow Keller (2011) for general morphology, Harris (1979) for sculpturing, and Wilson (1955) for pilosity. Measurements were made using an ocular micrometer on a Zeiss ${ }^{\circledR}$ Stemi SV 6 stereo microscope and follow those of Lattke (1995).

HL (Head Length): Length of head capsule in full-face view, from mid-point of anterior clypeal margin to mid-point of posterior head margin.

HW (Head Width): Maximum width of head capsule in full-face view.

ML (Mandibular length): From anterior clypeal margin to apex of fully closed mandibles.

WL (Weber's Length): The diagonal length of mesosoma in lateral view, from intersection point between pronotum and cervical shield to posteroventral angle of metapleuron.

SL (Scape Length): The maximum straight-line of the scape, excluding basal constriction.

EL (Eye Length): Maximum eye length measured along maximum diameter.

CI (Cephalic index): (HW/HL)x100

SI (Scape Index): (SL/HW) x 100

MI (Mandibular index): (ML/HL) x 100

OI (Ocular index): (EL/HL)x100

\section{Examined Material}

For comparative purposes, we examined workers of two mordax subgroup species with the following data. All specimens are deposited at Pe. Jesus Santiago Moure Collection (DZUP) of the Universidade Federal do Paraná, Curitiba, Brazil.
G. mordax: Peru, Cusco Amazónico, Villa Carmen Biol. Stn., 94km NE Cusco, $525 \mathrm{~m},-12.8940^{\circ}-71.4038^{\circ}$, 7.viii.2013, J. Lattke, 2 workers; Brazil, Rio de Janeiro, Ilha Grande, Trilha Jararaca, $-23.1811^{\circ}-44.3517^{\circ}$, Winkler, 01.xii.2009, J. M. Queiroz, 1 possible ergatoid; Brazil, São Paulo, São Paulo, Vila Mariana (Without date or collector), 1 worker,.

G. continua: Brazil, Espirito Santo, Regência, 23.i.1994,J. H. C. Delabie, 1 worker; Brazil, Goiás, Jataí, Faz. Sertãozinho, 843m, -17.9206 -51.7569', Winkler, 18.ii.2009, G. Santos,10 workers; Brazil, Goiás, Jataí, Faz. Santa Lúcia, $793 m,-17.8378^{\circ}-51.6567^{\circ}$, Winkler, 11.x.2008, Gilmar G. Santos, 2 workers, 3 workers; Venezuela, NE Cerro El Copey, 680m, $11.0065^{\circ}$ -63.8985 , 10.viii.2010, J. Lattke, 2 workers; Venezuela, Falcón, 950m, Cerro Los Caracoles, $10.8717^{\circ}-69.0274^{\circ}$, 5.ix.2002, J. Lattke, 2 workers; Venezuela, Falcón, 935m, Cerro Los Caracoles, 54km ESE Yaracal, $10.8718^{\circ}$ -69.0274, 24.iii.2002, J. Lattke.

We also examined high-resolution pictures of the types of four species, as well as those of two workers of $G$. stellae, all available on AntWeb (2019). Specimen identifier numbers as follows: G. boliviensis, CASENT0900556 (Photo: Ryan Perry); G. continua, CASENT0178676 (Photo: April Nobile); G. interrupta, CASENT0915912 (Photo: Anna Pal); G. mordax, CASENT0907188 (Photo: Will Ericson), CASENT0900547 (Photo: Ryan Perry); G. stellae, CASENT0281227 (Photo: Estella Ortega), INB0003662341 (Photo: Estella Ortega).

\section{Results}

Gnamptogenys rugimala Marcineiro \& Lattke, new species urn:lsid:zoobank.org:act:F06276EC-241A-40F6-BA3F-ED3F30E6574C

Type material. Holotype: Brazil, São Paulo, Salesópolis, E.B.B., 5-7. vii.1997, C. I. Yamamoto. Transect 1; Winkler 10. Specimen identifier DZUP 548842. One worker deposited in the MZSP collection, São Paulo, Brazil. Paratype: 1 worker, Brazil, Paraná, Tunas, Parque das Lauráceas,

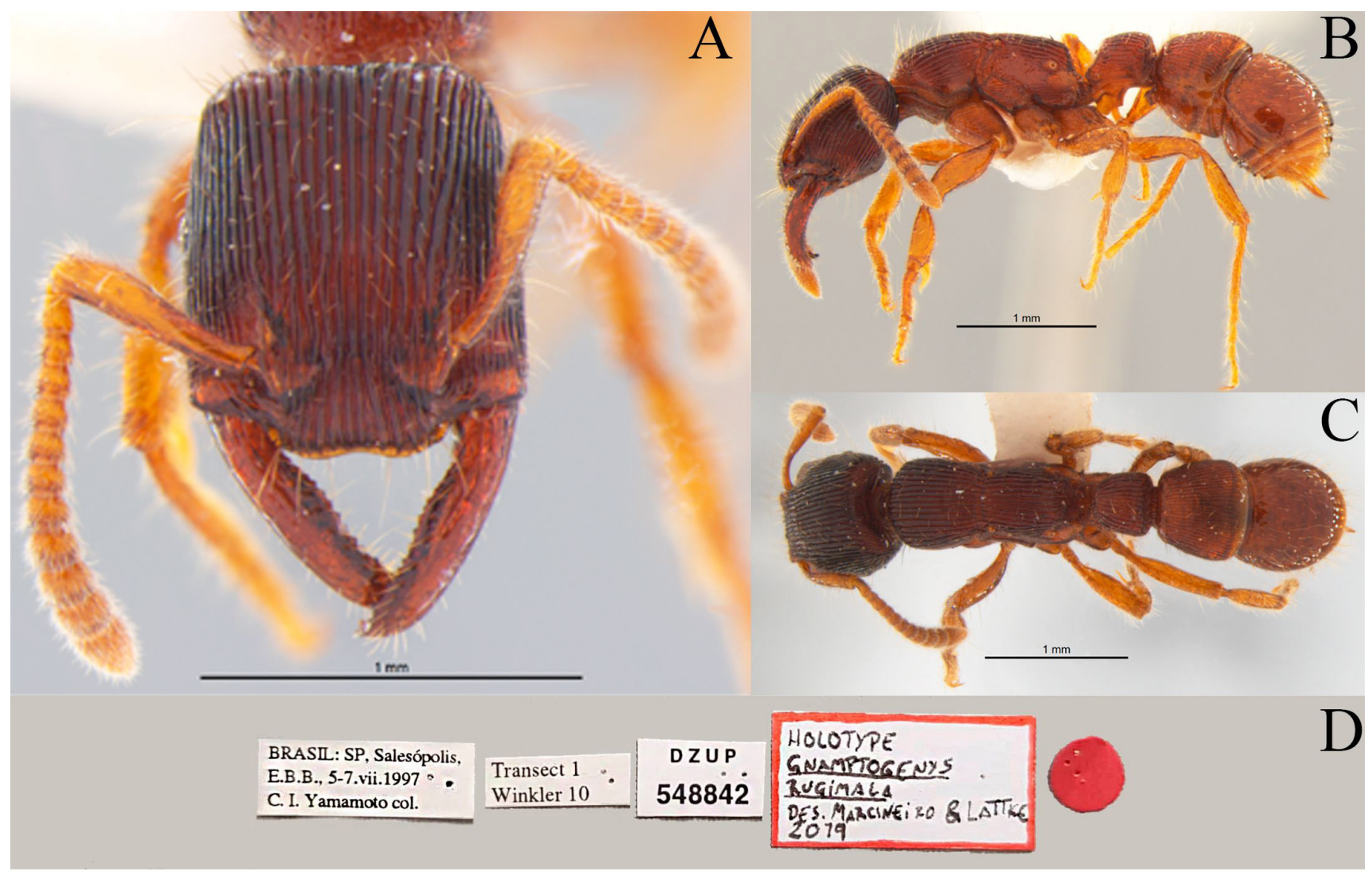

Figure 1. Holotype of Gnamptogenys rugimala Holotype A- Full-face view; B- Lateral view; C- Dorsal view, D- Specimen labels. 
-24.8544 $-48.7167^{\circ}, 21-29 . i 1.2001$, Silva \& Eberhardt. Transecto 1; Winkler 24. Specimen identifier DZUP 548843. One worker deposited in the MZSP collection, São Paulo, Brazil.

Etymology. The species epithet is derived from the Latin noun for jawbone, mala, and the Latin noun for crease or wrinkle, ruga.

Diagnosis. Within the mordax subgroup this species is recognized by the dorsum of the mandible with striae/rugae on at least one fourth of the mandible length; relative small eye size $(\mathrm{OI}<11)$; broad pronotal-anepisternal suture; second gastral tergite smooth and shining.

Worker description. Measurements and Indices. Holotype: HL- 1.04mm; HW- 0.92mm; ML- 0.39mm; WL- 1.41 mm; SL- 0.65mm; EL- 0.10mm; CI- 88.23; SI- 71.11; MI- 37.25; OI- 9.80. Paratype: HL- 1.14mm; HW- 0.98mm; ML- 0.47mm; WL- 1.63mm; SL- 0.74mm; EL- 0.12mm; CI- 86; SI- 76; MI- 41; OI- 11.

Head in dorsal view rectangular, posterior cephalic margin slightly concave, lateral margin straight to weakly convex, head slightly wider anteriorly than posteriorly; clypeus with anteromedian projection slightly wider than distance between frontal lobes, anterior margin of projection sinuous with broad median concavity and lateral convexity that extends posteriorly to rest of clypeus, clypeal lamella very narrow, best seen in anteroventral view of clypeus. Labrum with median concavity at apex, dorsal surface transversely imbricate, prementum smooth and shining, stipes with median rugulose sulcus; hypostoma finely imbricate. Cephalic dorsum and vertex longitudinally costate with sparse piligerous punctae, individual costula smooth and shining. Scape dorsoventrally flattened, failing to reach posterior cephalic border by slightly more than one apical width, dorsum smooth and shining with sparse punctulae. Mandible elongate, semifalcate, with broad basal convexity, internal and masticatory margins only distinguishable from one another by absence of teeth on internal margin, masticatory margin with series of low blunt denticles, better observed in oblique ventral view of mandible; dorsum with narrow band of rugulae and elongate punctae bordering masticatory margin from base to midlength of mandible, medioapically mostly smooth. Cephalic vertexal face concave, meeting dorsum at blunt angle; eye small, 6-8 ommatidia long, set just posterad to midlength of lateral cephalic margin in lateral view; ventral cephalic face with broadly diverging costulae.

Mesosoma in lateral view with slightly convex dorsal margin, metanotal groove shallow but distinct, propodeal dorsum bends onto declivity by approximate right angle; cervical shield rugose, pronotal dorsum and lateral face longitudinally costate; propleuron transversely striate; mesosomal dorsum continuously longitudinally costate; katepisternum longitudinally costulate; anterior two-thirds of metapleuron mostly shining with weak undulations, posterior one-third longitudinally costate, width of metapleuron relatively uniform. Space between anepisternum and posterolateral pronotal margin, relatively broad; anepisternum mostly rugulose, reduced to a narrow elevated strip extending obliquely ventrad from metathoracic spriacle to same height as dorsalmost margin of katepisternum. Propodeal spiracle facing slightly posteriorly, situated three opening diameters from propodeal declivitous margin. Mesometapleural suture well-impressed, scrobiculate; metapleural-propodeal suture indistinct; propodeum with narrow lateral crest; propodeal declivity longitudinally costate anteriorly and transversely costate posteriorly, forming an upside-down layered "T".

Petiole with short peduncle; in lateral view low, subquadrate, anterior margin oblique, broadly concave, dorsal margin slightly convex, posterior margin vertical, broadly convex; anterior face rugose, laterally and dorsally with longitudinal costae; posterior face narrow and transversely costate. Subpetiolar process in lateral view trapezoid, with longest base attached to sclerite, anterior margin broadly convex, ventral margin broadly concave and posterior margin almost straight; surface irregularly areolate. Anterior face of abdominal tergite III mostly smooth, dorsal and lateral faces longitudinally costate; abdominal sternite III with slightly weakened costae laterally, smooth and shining centrally with sparse punctae; rest of gastral segments smooth and shining with sparse punctulae. Procoxa transversely costate in lateral view, meso and metacoxa rugose; metacoxa with low dorsal lobe. Tibiae and femora mostly smooth and shining with sparse punctulae; probasitarsal notch with dense row of hairs and single median seta.

Head, thorax, dorsum of petiole and gaster without basal pubescence, with sparse erect to suberect yellow hairs, abundant pilosity on posterior gastral segments. Dorsum of antennal scape mostly devoid of pilosity except for posterior and anterior margins with subdecumbent hairs shorter than scape width. Antennae and legs yellowish brown to ferruginous; mandible brown; head, thorax and abdomen ferruginous brown to dark brown, sides lighter colored than dorsum, head dark brown to black.

\section{Geographic range}

This species is only known from the states of São Paulo and Paraná, southeastern Brazil.

\section{Biology}

Both ants were captured using Winkler extractors. Both of them came from an Atlantic forest region, classified as $\mathrm{Cfb}$ on Köppen climate classification, with annual rainfall of $1,550 \mathrm{~mm}$ and average temperature of $17^{\circ} \mathrm{C}$ through the year (Alvares et al., 2014). According to IBGE (2019), these areas are defined as Floresta Ombrófila Densa Montana in association with secondary vegetation. This vegetation is found in altitudes ranging from 400 to 1.000 meters and generally has a thin soil layer, bearing trees of 20 meters height on average, with small leaves and thin trunks. Both specimens were found at an approximate altitude of $850 \mathrm{~m}$

\section{Discussion}

Gnamptogenys rugimala is the only species in the subgroup with rugae on the mandibular dorsum. Gnamptogenys continua and G. boliviensis are very similar to this species, but present costulae on the second gastral tergite, and both species have a relatively larger eye diameter when compared with G. rugimala. The anterior clypeal margin of $G$. continua is weakly sinuous compared with G. rugimala. Gnamptogenys continua has a smooth and shining vertex, while in G. rugimala it is costate. The anterior pronotal face is mostly smooth and shining in $G$. continua, differing from the rugose face present in $G$. rugimala. Gnamptogenys continua has the metapleuron totally costulate, differing from $G$. rugimala which has the anterior metapleuron mostly smooth and shining. Gnamptogenys continua presents a reduced anepisternum, but it is distinct and does not present a broad pronotal-mesopleural suture, present in G. rugimala. Finally, G. continua bears a distinct anterolateral lobe on the propodeal declivity, poorly developed on G. rugimala. Compared with $G$. boliviensis the dorsal head sculpturing is very distinct, G. boliviensis presents a great number of striae, while G. rugimala presents thick costulae on its dorsum head. The pronotal-anepisternal suture in G. rugimala is broad, different from the narrow one present in $G$. boliviensis. Gnamptogenys interrupta and G. stellae do not have dorsal lobes on the metacoxa, readily separating them from $G$. rugimala before even considering other morphological 
characters. Gnamptogenys mordax is easily distinguishable by the presence of a large cuticular projection on the metacoxal dorsum. Besides that, G. mordax has much larger compound eyes (OI $>18$ ) placed slightly dorsolaterally on its head. Gnamptogenys rugimala presents smaller and laterally placed compound eyes that are hard to see in a full face view.

Key to mordax subgroup species identification (Lattke et al., 2007 in part).

1.- Metacoxal dorsum unarmed, at most with a low tubercle or swelling; clypeal lamella laterally with blunt angles in dorsal view, medially anteriorly projecting and with a small median concavity... 2 -Metacoxal dorsum with a lobe or tooth; clypeal lamella different from above .3

2.- Mandible with lateral striae; petiole posterior margin with a central concavity in dorsal view G. stellae -Mandible laterally smooth and shining; petiole posterior margin straight G. interrupta

3.- Mandibular dorsum rugose on at least the basal one fourth of its length; pronotal-anepisternal suture broad, resembling a rugous low area ... G. rugimala n. sp. -Mandibular dorsum mostly smooth and shining with sparse punctures; pronotal-anepisternal suture narrow, not resembling a rugous low area.

$\ldots . . .4$

4.- Metacoxal dorsum with a slender and parallel-sided lobe or tooth; $\mathrm{HL}>1.12 \mathrm{~mm}$; WL>1.81 mm. ... G. mordax -Metacoxal dorsum with a low triangular lobe; $\mathrm{HL}<1.12 \mathrm{~mm}$, $\mathrm{WL}<1.81 \mathrm{~mm}$ .5

5.-Dorsum of head striate; procoxa transversely striate; propodeal declivity inclined and relatively straight in lateral view; with weakly developed lateral lobes ... G. boliviensis -Cephalic dorsum costate; procoxa smooth and shining; propodeal declivity with a posterior concavity formed by well-developed anterolateral lobes G. continua

\section{Acknowledgements}

We thank the MZSP Hymenoptera collection personnel, particularly Mônica Antunes Ulyssea, for assistance and the UFPR Taxonline for providing their imaging facilities.

\section{Conflict of interest}

The authors declare no conflicts of interest.

\section{Compliance with ethical standards}

All applicable international, national, and/or institutional guidelines for care and use of animals were followed.

\section{Author contribution statement}

The first author presented the first draft. The second author first recognized the new species. Both authors contributed equally on writing and reviewed the manuscript.

\section{References}

Alvares, C. A., Stape, L., Sentelhas, P. C., Gonçalves, J. L. M., Sparovek, G., 2014. Köppen's climate classification map for Brazil. Meteorol.Z. 22 (6), 711-728.

AntWeb, 2019. Available in: https://www.antweb.org (accessed 16 September 2019).

Guénard, B., Weiser, M., Gomez, K., Narula, N., Economo, E. P., 2017. The Global Ant Biodiversity Informatics (GABI) database: a syntesis of ant species geographic distributions. Myrmecol. News 24, 83-89.

Harris, R. A., 1979. A Glossary of Surface Sculpturing. California: Department of Food and Agriculture, pp. 1-31. (Occasional Papers in Entomology, 28).

Instituto Brasileiro de Geografia e Estatística - IBGE, 2019. Available in: https://bdiaweb.ibge.gov.br/\#/consulta/vegetacao (accessed 26 August 2019).

Keller, R. A., 2011. A phylogenetic analysis of ant morphology (Hymenoptera: Formicidae) with special reference to the poneromorph subfamilies. Bull. Am. Mus. Nat. Hist. (355), 1-90.

Lattke, J. E., 1990. Revisión del Género Gnamptogenys en Venezuela (Hymenoptera: formicidae). Acta Terramaris 2, 1-47.

Lattke, J. E., 1995. Revision of the Ant Genus Gnamptogenys in the New World (Hymenoptera: formicidae). J. Hymenopt. Res. 4, 137-193.

Lattke, J. E., Fernández, F., Palacio, G. E. E., 2007. Identification of the species of Gnamptogenys Roger in the Americas. In: Snelling, R.R., Fisher, B.L., Ward, P.S. (Eds.), Advances in Ant Systematics (Hymenoptera: Formicidae): Homage to E. O. Wilson: 50 Years of Contributions. American Entomological Institute, Gainesville, pp. 254-270. (Memoirs of the American Entomological Institute, 80).

Longino, J. T., 1998. Ants of Costa Rica. Available in: http:// ants.biology.utah.edu/AntsofCostaRica.html (accessed 24 Septemper 2019).

Wilson, E. O., 1955. A monographic revision of the ant genus Lasius. Bull. Mus. Comp. Zool. 113 (1), 1-204. 